\title{
The Minimum Water Consumption of Ethanol Production via Biomass Fermentation
}

\author{
P.H. Pfromm* \\ Department of Chemical Engineering, Kansas State University, Manhattan, Kansas, USA
}

\begin{abstract}
The water consumption of fermentation-based bio-ethanol production has recently begun to attract public attention. We calculate a minimum consumption of $2.85 \mathrm{gal}$ water/gal of ethanol produced assuming zero liquid discharge and otherwise current industrial practice data. Including cooling tower blowdown and drift this value may increase to on the order of $4 \mathrm{gal}$ water/gal of ethanol produced. Reduction of the thermal energy input to the process is vital to reduce this irretrievable water consumption.
\end{abstract}

\section{INTRODUCTION}

It appears that ethanol production from biomass via yeast-based fermentation ("bio-ethanol") will play an increasingly important role world wide (4.2 billion gallons produced in Brazil from May 2005 to April 2006, 6\% increase projected for 2006/2007 [1], projected 12 billion gallons ethanol per year in 2012 in the U.S. [2]). Water consumption of bio-ethanol facilities has become controversial in the public eye [3-5]. The minimum water consumption of a state-of-the-art ethanol facility is calculated here under the very stringent assumption of complete process water recycling. The calculated minimum water consumption of 2.85 gal water/gal of ethanol produced is essentially due to the significant cooling needs with the water irretrievably lost as vapor to the atmosphere. The cooling needs result to a large extent from the energy input for ethanol/water separation among other process steps.

There is still a lively discussion in regard to the merits and demerits of bio-ethanol [6,7]. Nevertheless, it appears to be an undeniable fact that there will be very significant and increasing world-wide bio-ethanol production for years to come.

One aspect of bio-ethanol production is the water consumption for the process to convert any biomass to ethanol. Here we deliberately exclude the water needs to grow the biomass. This water demand may be open to significant change and perhaps reduction through choice of crops (corn vs. grasses etc.). The reported irrigation needs of growing corn (U.S. average in 2003 about 785 gallons of water per gallon of ethanol produced, based on [8], and a yield of 2.8 gallons of ethanol per bushel of corn) certainly dwarf the reported water consumption range of 3-15 gallons per gallon of ethanol (below) for the corn-to-ethanol conversion process based on fermentation. However, other "energy crops" may use significantly less irrigation water and perhaps avoid irrigation altogether [9]. The considerations shown below are largely independent of the type of crop.

A wide range of water consumption for the conversion process is reported ranging from about 3 gallons of water per

*Address correspondence to this author at the Department of Chemical Engineering, Kansas State University, Manhattan, Kansas, USA; E-mail: pfromm@ksu.edu gallon of ethanol to perhaps as much as 15 gallons of water per gallon of ethanol [10]. One might be tempted to focus on the fact that for example for fermentation of corn it is required to use a water-to-corn mass ratio of about 9 to 1 to prepare a fermentable mash. Recycling of this process water may appear to be important. Claims such as "zero liquid discharge" [11] may elicit hope for very low water consumption of bio-ethanol facilities.

Here we will assume complete recycling of water within the process, except for water that is evaporated as a heat sink and water discharged as a constituent of byproducts such as distiller's dried grains (DDG). It will be seen that the water consumption of a completely "closed cycle" (no liquid waste water) but otherwise state of the art bio-ethanol facility is still very significant and inescapable.

The fundamental issue limiting the minimum water consumption is the need of an economical heat sink for the large amount of thermal energy currently needed to process any biomass to fermentation-based bio-ethanol. Even the most advantageous assumptions (below) lead to significant and non-recyclable water consumption as a heat sink. This water consumption can best be reduced by reducing the thermal energy intake. This, in turn, hinges to a good portion on reducing the thermal energy demand of the ethanol-water separation which accounts for on the order of $40 \%$ of the total thermal energy intake to produce bio-ethanol [12]. The focus here is to offer a simple method to estimate the water consumption in state of the art or future processes based on the first law of thermodynamics.

\section{METHODOLOGY}

The fundamental fact is that the very significant thermal energy intake of state-of-the-art bio-ethanol facilities must be balanced by an appropriate heat sink, here assumed to be evaporation of water in a cooling tower and other equipment such as driers. A simple analysis of the bio-ethanol production process based on the first law of thermodynamics (steady-state energy balance) is offered. Assumptions are:

1. The process (Fig. (1)) takes in moist corn, liquid cooling water, and energy, and produces fuel grade ethanol, byproducts such as DDG (assumed 10wt\% water in DDG, $14.8 \mathrm{~kg}$ DDG/gallon of ethanol), water vapor, and a moist gaseous $\mathrm{CO}_{2}$ stream. Fermentation is 
carried out using yeast. Auxiliary process chemicals are neglected. A yield of 2.8 gallons of ethanol per bushel $(25.4 \mathrm{~kg})$ of moist corn $(16 \mathrm{wt} \%$ water) is assumed.

2. The boundary of the process for the energy and water balances is as shown in Fig. (1).

3. All materials except liquid cooling water and ethanol to storage (see below) are at ambient temperature $\left(20^{\circ} \mathrm{C}\right)$ and $1 \mathrm{~atm}$ when crossing the system boundary shown in Fig. (1).

4. The incoming liquid cooling water is discharged as vapor to the atmosphere at ambient conditions in a forced-draft cooling tower [13] as is the current state of the art [14] and in other processes such as DDG drying [15]. Water needed for cooling tower blowdown to purge minerals from the cooling cycles and to replace drift (water drops entrained in the vapor leaving the cooling tower) is neglected. Almost all the water entering with the corn is also assumed to be available for evaporation (see Fig. (2)).

5. The exothermal nature of the fermentation process is neglected in the energy balance to bias the calculation towards the lowest possible cooling water consumption.

6. Any heat losses from process equipment like distillation columns to the atmosphere are neglected. Assuming good insulation is advantageous since this reduces the overall energy demand and thereby the cooling load.
7. All energy inputs are neglected except for the thermal energy assumed to be transferred to the process by process steam. The steam is assumed to be raised in a natural gas fired boiler at $77 \%$ thermal efficiency.

8. All process water besides the cooling water is assumed to be completely recycled. Water contained in the incoming corn is assumed to be discharged with the byproducts (distiller's dried grains for example), the moist gaseous $\mathrm{CO}_{2}$ stream from fermentation, and as traces in fuel ethanol. The majority of the water in the incoming corn is assumed available for evaporative cooling as a best-case assumption for the lowest water demand.

9. Ethanol product is assumed to be liquid at $40^{\circ} \mathrm{C}$ when sent from the process to storage. Ethanol condensation after final trace water removal by adsorption [15] or membrane permeation is assumed by using cooling water since air cooling requires significant capital and operating expense (see below for discussion of air cooling as a process heat sink).

Fig. (1) shows the overall concept.

The optimistic assumption of complete in-process water recycling made here is perhaps not easily realized in practice. Specialty separation processes would likely be needed as "kidneys" to continuously remove highly water soluble materials like salts and acids. These materials may otherwise build up in the water cycles and eventually disturb the process, as has been seen in the forest products industry $[16,17]$. Selective process kidneys may add significant capital and operating costs but this may be acceptable if water cost, wa-

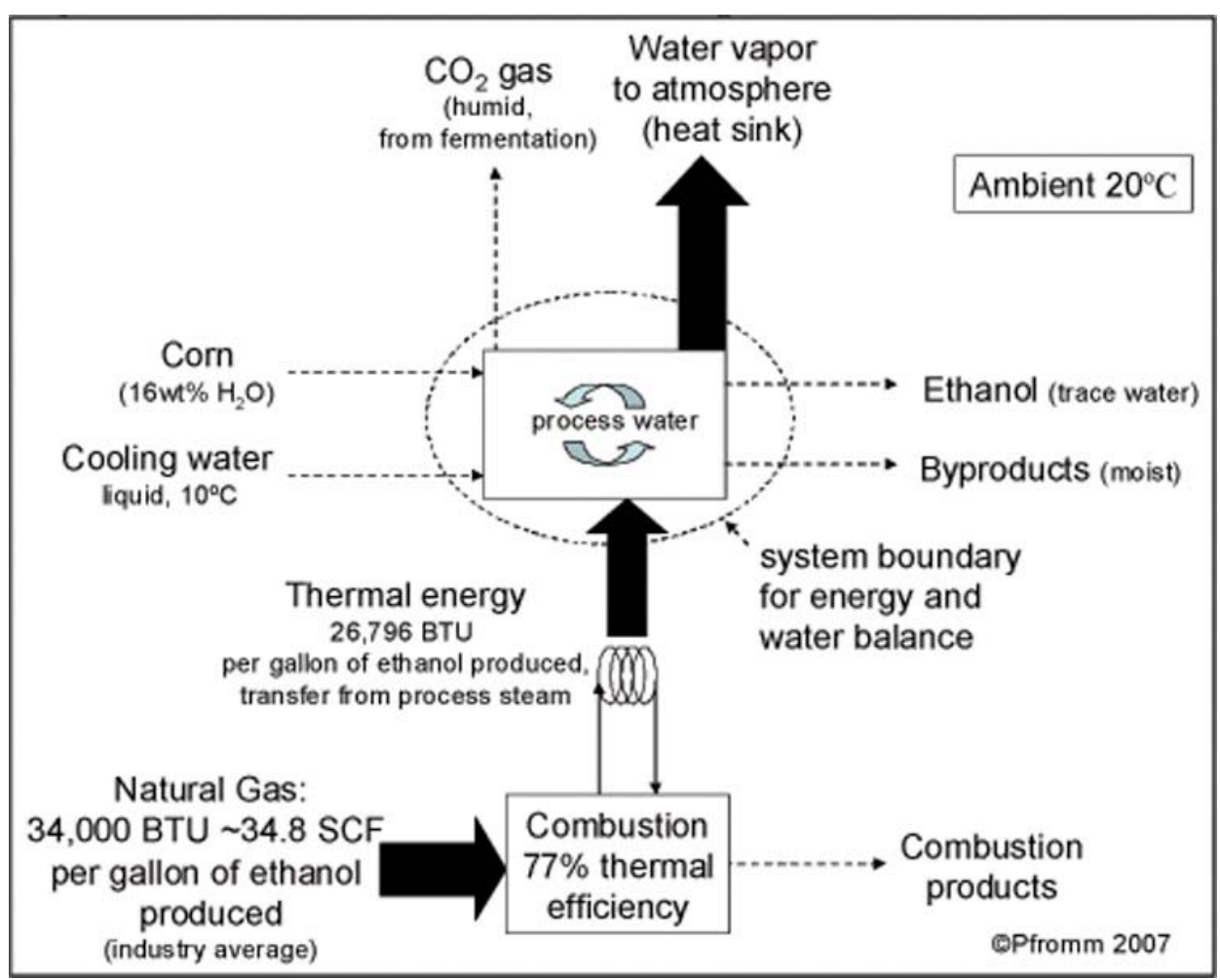

Fig. (1). Overall schematic for an energy balance of corn-based bio-ethanol production. Main energy flows are shown as solid arrows. Mass flows are show as dashed arrows. All materials cross the system boundary at ambient temperature except cooling water $\left(10^{\circ} \mathrm{C}\right)$ and product ethanol $\left(40^{\circ} \mathrm{C}\right)$. 
ter availability, and waste water discharge become limiting factors.

\section{RESULTS AND DISCUSSION}

The lower heating value of ethanol is about 76,330 BTU/gallon [18]. The average thermal energy consumption for bio-ethanol is assumed here to be 34,800 BTU of thermal energy per gallon of fuel ethanol produced [19]. This is corroborated elsewhere [14,20]. It is interesting that the Illinois River, LLC facility cited above is claimed to be "zero wastewater effluent", which is an assumption that is also made here. This does however by no means equate to zero or near-zero water consumption.

We assume that the above thermal energy input of 34,800 BTU per gallon of ethanol is via a boiler where natural gas is combusted and $77 \%$ of the liberated heat is transferred to process steam. 26,796 BTU per gallon of ethanol produced will thereby enter the process. A large portion of this energy is used to separate ethanol from water by distillation and adsorption to reach a purity sufficient for fuel applications.

Under the assumptions above the first law of thermodynamics requires that at steady state the heat supplied to the process must be discharged to the environment and one can derive a simplified approximate energy balance,

$\mathrm{E}_{\text {total,thermal }} \varepsilon_{\text {nat.gas }} \mathrm{V}_{\mathrm{EtOH}}=$

$\mathrm{V}_{\mathrm{H} 2 \mathrm{O}} \rho_{\mathrm{H} 2 \mathrm{O}}\left(\Delta \mathrm{h}_{\text {latent,H2O}}+\Delta \mathrm{T} \mathrm{c}_{\mathrm{P}}\right) \ldots$

where $E_{\text {total,thermal }}$ is the specific thermal energy from natural gas combustion in $\mathbf{J}$ per gallon of ethanol produced (here from above and converted to be taken as 9,692,376 J/l of ethanol), $\varepsilon_{\text {nat.gas }}$ is the thermal efficiency for process steam production from combustion of natural gas (here 0.77 ), $\mathrm{V}_{\mathrm{EtOH}}$ is the volume of ethanol produced in liters, $\mathrm{V}_{\mathrm{H} 2 \mathrm{O}}$ is the volume of cooling water in liters, $\rho_{\mathrm{H} 2 \mathrm{O}}$ is the density of water (1 $\mathrm{kg} / \mathrm{l}), \Delta \mathrm{T}$ from the cooling water intake to the temperature where evaporation in the cooling tower takes place is taken as $25 \mathrm{~K}, \mathrm{c}_{\mathrm{P}}$ is the average specific heat capacity of liquid water (here taken as $4178.2 \mathrm{~J} / \mathrm{kg} \mathrm{K}$ ), and $\Delta \mathrm{h}_{\text {latent,H2O }}$ is the average enthalpy of vaporization of water (taken as 2,264,000 $\mathrm{J} / \mathrm{kg}$ ).

Solving for $\mathrm{V}_{\mathrm{H} 2 \mathrm{O}} / \mathrm{V}_{\mathrm{EtOH}}$ yields 3.15 gallons of cooling water needed for one gallon of ethanol to be produced. Since most of the water coming in with the corn is assumed available for evaporative cooling (about 0.3 gallons per gallon of ethanol produced) cooling water intake can be reduced to 2.85 gallons of cooling water per gallon of ethanol produced (Fig. (2)). This cooling water can not be recycled or recovered since it is assumed to be discharged as vapor to the ambient air. The cooling tower blowdown and drift losses may increase this water consumption by $30 \%$ or more [14].

Eq. 2 below (based on eq. 1) gives a simple estimate of the minimum water consumption based on the gross thermal energy input when natural gas and evaporative cooling is used:

$\mathrm{V}_{\mathrm{H} 2 \mathrm{O}} / \mathrm{V}_{\mathrm{EtOH}}=\varepsilon_{\text {nat.gas }} 4.217410^{-7} \mathrm{E}_{\text {total,thermal } \cdots}$

If thermal energy to raise process steam is harvested from combustion of coal or other fuels instead of natural gas one will have to replace $\varepsilon_{\text {nat.gas }}$ with the proper value for the particular fuel and combustion process(es).

All assumptions made here are biased towards arriving at a minimum water consumption that is not likely to be achieved in practice. However, this result serves as a baseline for any claims or estimates towards water consumption for the fermentation-based bio-ethanol process or other processes such as for bio-butanol.

The minimum water consumption calculated here does not depend on the feedstock. For some feedstocks the thermal energy consumption upstream of fermentation may be

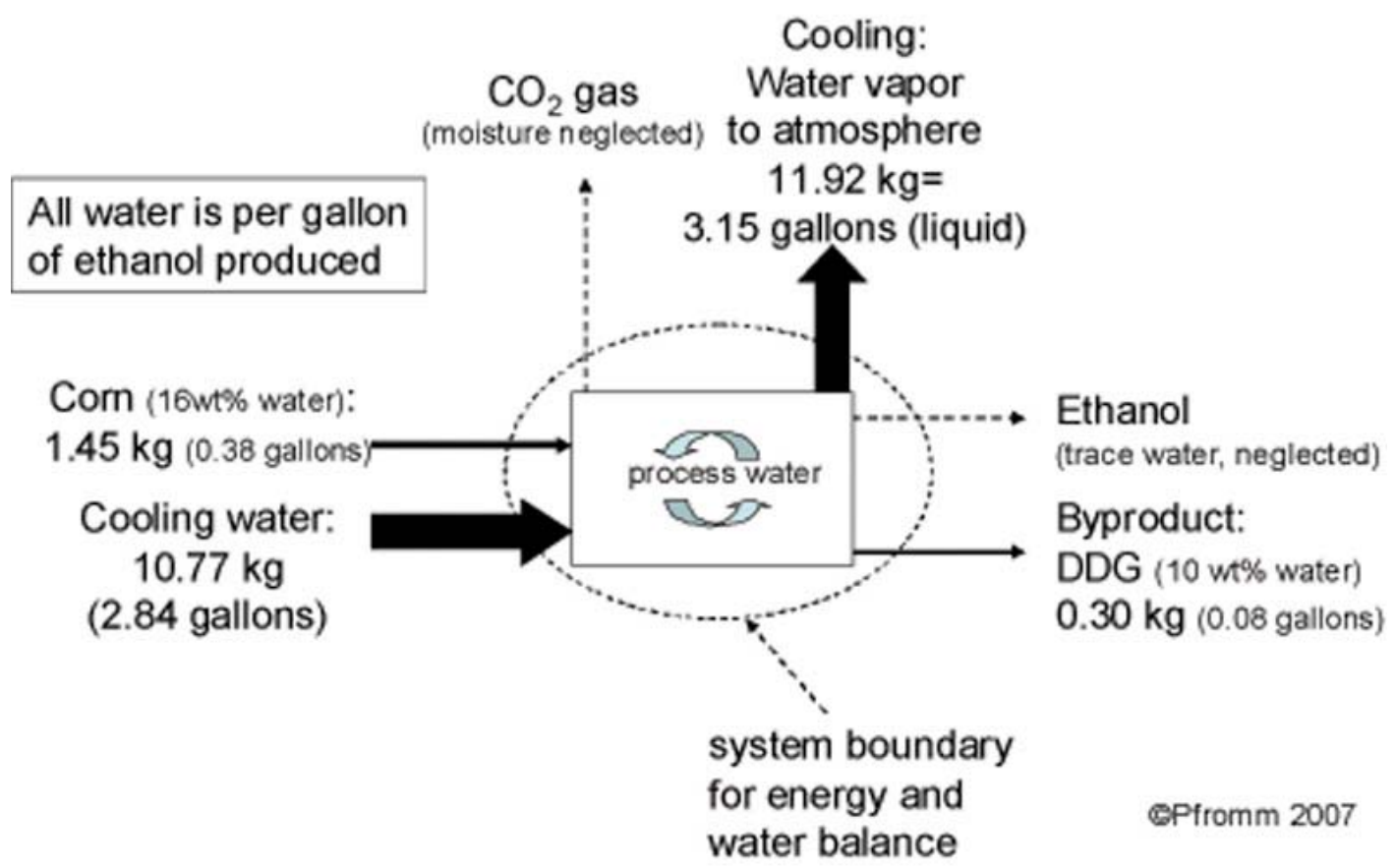

Fig. (2). Overall schematic for a water balance of corn-based bio-ethanol production with evaporative cooling as the heat sink and an energy input as shown in Fig. (1). Dashed arrows are neglected. 
different than the dry mill corn based process. The energy intensive separation of ethanol from a dilute aqueous mixture (fermentation broth) can not be avoided as long as fermentation is used. Some fundamental efforts are under way to further increase the final concentration of ethanol in fermentation broth. However, physical (solubility of cell components) and biochemical (metabolic) toxicity limits are in place that will likely limit the best results of these efforts so that one is still confronted with the separation problem of dilute alcohol in water after fermentation. Other efforts focus on reducing the thermal energy demand of drying to produce DDG. Any reduction in overall energy demand such as heat recovery from vapors produced during DDG drying will reduce cooling water demand if complete in-process water recycling is assumed. If a liquid water discharge results from this energy recycling then the overall water consumption may actually increase since heating liquid water is a poor heat sink compared to vaporization of water.

One alternative to reduce water consumption might be to use a "dry" cooling system (essentially no water evaporated) where electrically driven blowers direct ambient air over a heat exchanger surface for air to receive rejected process heat from cooling water circulated in a closed cycle. "Dry" cooling will consume essentially no water but will cause a significant increase in capital cost, perhaps ten-fold or more compared to evaporative cooling [21]. Cooling system operating costs will increase because "dry" cooling requires four to six times the electrical energy compared to "wet" evaporative systems, mainly to supply the motive power for cooling air [21]. It appears that dry cooling applied to reduce water use in bio-ethanol facilities is probably not an economically feasible proposal at this time.

\section{CONCLUSION}

The water consumption of state of the art fermentationbased bio-ethanol production from biomass with the customary and economical evaporative cooling system will be at minimum about 2.85 gallons of water per gallon of ethanol. This is based on the industry average natural gas consumption equivalent to $34,800 \mathrm{BTU}$ (34.8 standard cubic feet of natural gas) per gallon of ethanol produced. This cooling water is evaporated in a cooling tower and released as vapor as a heat sink for the energy input of the process and can not be recycled. This water consumption is a minimum because it is calculated for a hypothetical zero-wastewater discharge process (complete in-process water recycling). The water consumption can however be proportionally decreased by reducing the thermal energy demand for the overall process, and specifically for ethanol/water separation. Any thermal energy reduction would then yield the double benefit of improving the energy balance for bio-ethanol, and reducing water consumption. "Dry" cooling systems with negligible water use but with ambient air as the heat sink would likely have very significantly increased capital ( 10 fold) and operating ( 4-6 fold) costs when similar estimates done for the power industry are consulted.

In summary, the results presented here allow simple predictions of the minimum water consumption and the impact of increased energy efficiency on water consumption in the fermentation-based bio-ethanol industry. A strong effort to reduce the energy demand for bio-ethanol production is needed not only to improve the energy balance and energy costs of bio-ethanol, but also to reduce water consumption.

\section{REFERENCES}

[1] M. Perkins, and S. Barros, "Brazil Bio-Fuels Annual 2006", Global Agricultural Information Network Report BR6008, U.S. Department of Agriculture, Foreign Agricultural Service, May 2006. [Online] Available: http://www.fas.usda.gov/gainfiles/200606/ 146197970.pdf. [Accessed Oct. 15, 2007].

[2] Anon., "U.S. Department of Agriculture Agricultural Projections 2016", USDA report OCE2007-1, February 2007. [Online] Available: http://www.usda.gov/oce/commodity/archive_projections/ USDA\%20Agricultural\%20Projections\%20to\%202016.pdf. [Accessed Oct. 15, 2007].

[3] B. Lambrecht, "States grappling with the prospect of thirsty ethanol plants", St. Louis Post-Dispatch, April 14, 2007.

[4] Anon., "Ethanol faces big hurdle: water use", St. Petersburg Times, May 28, 2007. [Online] Available: http://www.sptimes. com/2007/05/28/Hillsborough/Ethanol_faces_big_hur.shtml. [Accessed Oct. 15, 2007].

[5] Anon., "State's water supply unclear because of budget cuts", The Associated Press State and Local Wire, December 6, 2006.

[6] D. Pimentel, T. W. Patzek, and C. Gerald, "Ethanol production: energy, economic, and environmental losses", Reviews of Environmental Contamination and Toxicology, vol.189, pp. 25-41, 2007.

[7] H. Shapouri, J. A. Duffield, and M. Wang, "The energy balance of corn ethanol revisited", Transactions of the ASAE, vol. 46, no. 4, pp. 59-968, 2003.

[8] Anon., "2002 Census of Agriculture, Farm \& Ranch Irrigation Survey (2003)", Table 28, USDA, November 2004. [Online] Available: http://www.nass.usda.gov/census/census02/fris/fris03.pdf [Accessed Oct. 25, 2007].

[9] E. Heaton, T. Voigt, and S. P. Long, "A quantitative review comparing the yields of two candidate C-4 perennial biomass crops in relation to nitrogen, temperature and water", Biomass \& Bioenergy, vol. 27, no. 1, pp. 21-30 2004.

[10] D. Keeney, and M. Muller, "Water Use by Ethanol Plants Potential Challenges", Institute for Agriculture and Trade Policy. Minneapolis, Minnesota, 2006. [Online] Available: http://www.ef.org/ documents/IATP_water.pdf. [Accessed Oct. 15, 2007].

[11] Anon., U.S. Water Services, press release December 5, 2006. [Online] Available: http://uswaterservices.com/downloads/Pa-cific\%20 Ethanol.pdf [Accessed Oct. 8, 2007].

[12] Anon., Corporate literature. Lurgi Oel, Gas, Chemie GmbH 2005.

[13] E. Bagnoli, R. W. Norris, T. M. Flynn and K. D. Timmerhaus. "Psychrometry, Evaporative Cooling, Refrigeration, and Cryogenic Processes", in: R. H. Perry, D. W. Green, Ed. Perry's Chemical Engineers' Handbook, sixth Edition. New York: McGraw-Hill, 1984.

[14] M. Fatigati, in: H. Jessen, "Opportunities to conserve water", Ethanol Producer Magazine, February 2007. [Online] Available: http://ethanolproducer.com/article.jsp?article_id=2734. [Accessed Oct. 15, 2007].

[15] J. R. Kwiatkovski, A. J. McAloon, F. Taylor, and D. B. Johnston. "Modeling the process and costs of fuel ethanol production by the corn dry-grind process", Industrial Crops and Production, vol. 23, no. 3, pp. 288-296, 2006.

[16] P. H. Pfromm, S.-P. Tsai, and M. Henry, "Electrodialysis for Bleach Effluent Recycling in Kraft Pulp Production", The Canadian Journal of Chemical Engineering, vol. 77, pp. 1-8, 1999.

[17] P. H. Pfromm, "Low Effluent Processing in the Pulp and Paper Industry: Electrodialysis for Continuous Selective Chloride Removal", Separation Science and Technology, vol. 32, no. 18, pp. 2913-2926, 1997.

[18] Anon., "Properties of Fuels", U.S. Department of energy, Energy efficiency and Renewable Energy, Alternative Fuels \& Advanced Vehicles Data Center. [Online] Available: http://www. eere.energy.gov/afdc/pdfs/fueltable.pdf. [Accessed Jan. 10, 2008].

[19] H. Shapouri, and P. Gallagher, "USDA's 2002 Ethanol Cost-ofProduction Survey", U.S. Department of Agriculture Agricultural Economic Report \#841, July 2005. [Online] Available: http:// www.ncga.com/ethanol/pdfs/031506USDACostOfProduction.pdf. [Accessed Oct. 15, 2007]. 
[20] Anon., "Illinois River Energy, LLC, Construction". October 15, 2006. [Online] Available: http://www.illinoisriverenergy.com/ $\mathrm{html} /$ construction.html. [Accessed Oct. 5, 2007].

[21] J. S. Maulbetsch, "Comparison of alternate cooling technologies for California power plants", California Energy Commission and Elec- trical Power Research Institute (EPRI), Final Report, February 2002. [Online] Available: http://www.energy.ca.gov/reports/200207-09_500-02-079F.PDF. [Accessed Oct. 15, 2007]. 